\title{
IoT Based Security Alerts for the Safety of Industrial Area
}

\author{
K.G.Kharade ${ }^{\text {a, }}$, S.K.Kharade a, V.R.Sonawane ${ }^{\text {a }}$, S.S.Bhamre ${ }^{\text {a }}$, \\ S.V.Katkar ${ }^{b}$, R.K.Kamat ${ }^{\text {a }}$ \\ ${ }^{a}$ Department of Computer Science, Shivaji University, Kolhapur, MH \\ ${ }^{\mathrm{b}}$ Department of Information Technology, MVP's K.B.T. College of Engineering, Nashik, MH
}

\begin{abstract}
The security of any business plays a vital role. All enterprises expect high security because of the increase in robbery. It is challenging to manage security with traditional ways of protection. This paper emphasizes the sensorbased security system to protect against any unwanted entry in the business area. This system is developed using IoT-based sensors, and electronic materials develop the security system. The present scenario ensures protection and security have become inevitably necessary. There is regressive progress in the protection sector as the influence of new technology is hitting its height. It's well-known as a modern home when there is a current home with minimal human effort. This technology aims to automate industrial area security and partially replace the security individual, enabling us to monitor unsuspecting activities and be warned during critical situations. Since wireless and emerging technology is taking place, an automated intelligent protection system is being introduced.
\end{abstract}

Keywords. Home automation, Home appliances, IoT, Motion Sensors

\section{Introduction}

Internet of Things It is the concept of connecting real-world objects to the internet and monitoring their performance remotely through the internet. It envisions the interconnected and testable items connected via the internet [3]. IoT is used to consolidate real, virtual, and computerized conditions to make a savvy domain that simplifies life [20]. It is another period of synchronization and communication between machines and objects or situations command-and-and-and-control methodology can benefit our lives. Recently, technology has been making a recovery with a slant or rising, or running, as well as something that tilts, such as the Internet of Things [7]. Innovation is required to govern the world within a couple of years. Items can communicate with data and can make vital choices at whatever point is required. When items can speak with one another using the web, we have to take a favorable remote access position [1]. The ultimate goal of IoT is to make artificial life frameworks use new robotics frameworks rather than using new frameworks to automate human-based ones. The sensor-based business has many benefits; it is flexible, simple to use, easily applied, and inexpensive [2]. Almost all current computing devices can be connected to $\mathrm{WiFi}$ or be associated with a smartphone and home computers. Apart from that, they

\footnotetext{
${ }^{1}$ K.G.Kharade ,Department of Computer Science, Shivaji University, Kolhapur, MH, India Email: kabirkharade@gmail.com
} 
don't require the use of one another, these tools to work, nor can they exchange information with one another, these devices [22]. Current home security and surveillance systems are trying to overcome the problems of conventional security systems [4]. Using only motion sensors, you can secure your home from anywhere in the world; you can gain remote access to the system to know the current state of the IoT. People enrich their lives through the provision of a variety of service options [5]. It seeks to meet people's and enable their simple needs [18]. The most innovative and most cost-effective way to handle all things regarding your house, in general, is to replace all the things you have with the items you want [21]. Advances in automation have eased life in all areas of our lives. The adage "automation" is replacing "manuality" these days [23]. There has been a recent explosion in the number of internet usage, and emerging internet technologies, such as the Internet of Things, are part and parcel of daily life now-day activities [19]. While you're working, the Internet of Things network includes machines and consumer goods made to communicate and get the job done when you aren't .

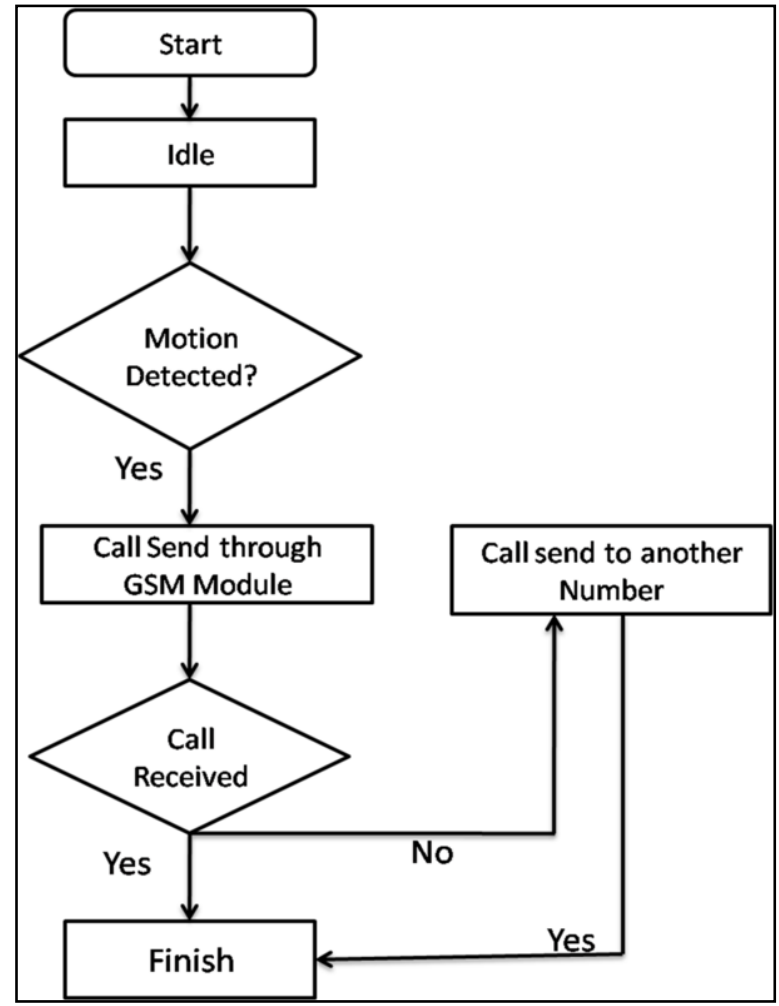

Figure 1. Flowchart of the system

\section{Existing System}

[26] Observed that, in this rapid implementation of networked digital technology is found in the home. It connects new and existing devices to a higher level of automation 
and provides additional options for existing ones. the remote control has started to develop. [27] Stated, In IoT, internet connectivity is available for everything in the physical world, including things like smart meters, intelligent door locks, intelligent appliances, and other objects. Virtualization allows various processes to be done without synchronizing between the hardware devices. Without restricting the number of locations, the Internet of Things can run multiple tasks on unlimited resources and distant locations using intelligent devices and fast networks. [28] described Smart houses would gain in desirability due to the benefits of automation. The main problem with safety and security in the home is that they have been neglected for too long. The safety and security of people in the province of modern technology focus on Home Automation features, including a camera functionality that supports it. If movement is detected at the house's entrance, a warning is sent that includes a real-time picture of the entrance. The house owner will receive this message from the internet, allowing the app to send a notification. [29] reported, Smart homes require complexity control in their various gadgets, which are fundamentally electronic appliances. Advanced mobile phones are now highlighted consummate and can be made to conveyor interface with different devices in an ad-hoc network with available Bluetooth and WiFi options. With the appearance of portable phones, Mobile application improvement has seen a significant episode. Figure 1 Flowchart of the system to utilize this chance for a smart home, we select the cell phone ordinarily because it is found in an ordinary family that can be participated in a brief organization inside a home with electronic equipment. Android, by Google Inc., gives the stage to advance the portable applications for the Android gadgets.

\section{The Need for PIR Sensor}

PIR is a short form of Passive InfraRed motion detectors. The logic behind the working of PIR. is simple. Both humans and animals dissipate heat; the fluctuation in the surroundings' emitted energy can be measured. When a human enters the surroundings, the sensor detects the radiated energy's change within the surroundings, concerning the previously noted energy levels [5].

\section{Proposed System}

The system is designed to give alerts when motion detects in prohibited areas. For this, once the space and time of surveillance are selected, adding the list of mobile numbers over which you want to receive alerts. The system will notify the registered mobile numbers with an alert when the motion is detected in the designated area of surveillance. The Motion detection sensor is connected to Arduino to see all the activities in the prescribed zone. It will trigger action through the GSM module to the specified numbers. The fail-safe mechanism is available if the first registered number is unavailable; the system redirects the call to the successive number registered. Once notified, the user will be able to take necessary action depending on the need. 


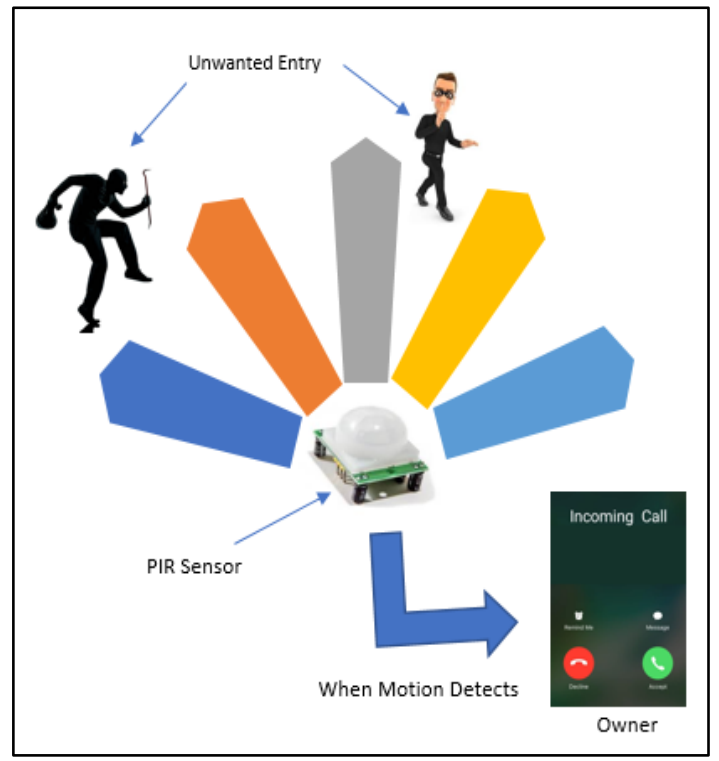

Figure 2. A working model of the system

\section{Hardware Requirement}

Following hardware list required to develop the system [13] [16]

a) GSM Module SIM 900A: This module is commonly used in mobile phones and PDAs. Also useful for IoT (Internet of Things) and Embedded Applications development, it can also be used as a module. This SIM900A radio engine works on frequencies that use the terms EGSM $900 \mathrm{MHz}$ and DCS $1800 \mathrm{MHz}$.

b) PIR Sensor: The sensors used to detect human motion work well with PIR motion sensors.

c) $5 \mathrm{~V}$ power supply: One of the most popular power supplies today is a $5 \mathrm{~V}$ model. When the output of a regulated 5VDC power supply is being regulated, a dissipative regulating circuit is used.

d) Node MCU: The Node MCU project offers free hardware schematics and board designs for open source design prototyping.

e) Data cable: Cables used to transfer electronic data from a source to a destination are referred to as data cables. type of data cabling is either copper or fibre optics.

f) SIM Card: The SIM cards are small, removable, and transferable chips that contain chips that can be placed in other phones.

\section{Advantages of the System}

This system has the following advantages;

a) Low-cost system and that can take care of industries in the absence. 
b) No need to invest in a separate smartphone.

c) The system is platform-independent

d) The same device can be deployed for many industries where security is a significant concern in our absence [14].

\section{Specialized area where this system can be implemented}

This system can be implemented in the areas mentioned below, but not limited to [15].

a) Demilitarized zone

b) Home/Shop security

c) Hospitals

d) Hotels

e) Laboratories

f) Penitentiary

g) Banks

h) Institutes

\section{Result and Discussion}

As discussed in Figure 2, it is observed that once you install this system in your enterprise, it will keep checking all the entries on their premises. Once it found any unwanted access, first it will play an alarm, and at the same time, it will call the number specified. If the person didn't receive the call, the call would be transferred to the following number available in the system. In this way, security can be maintained of your enterprise in your absence. The developed method is very cost-effective but valuable. There is a provision of deciding the range of your system with the help of potentiometer available in the system.

\section{Conclusion}

This system has been developed at significantly less cost but having huge benefits. Once you implement this system into your business, the consumer does not need to think about the security issues as this system will take its care. Android-based automation offers a simple and attractive interface and makes the device more stable and versatile. To connect with the home automation system, we use mobile devices. To power the computers, $\mathrm{WiFi}$ is used to communicate between the Arduino and the android program. The overall device is constructed using the SIM 900A Specification GSM module, PIR sensor, power supply, MCU node, data cable, and SIM card.

\section{References}

[1] Dongale, T. D., Katkar, S. V., Khot, K. V., More, K. V., Delekar, S. D., Bhosale, P. N., \& Kamat, R. K. Simulation of randomly textured tandem silicon solar cells using quadratic complex rational function approach along with artificial neural network. Journal of Nanoengineering and Nanomanufacturing, VI(2), 2016,103-108. 
[2] Dongale, T. D., Kharade, K. G., Naik, G. M., \& Kamat, R. K. Artificial Neural Network Modeling of NixMnxOx based Thermistor for Predicative Synthesis and Characterization. Journal of Nano And Electronic Physics,2017, 03042(1)-03042(4).

[3] Indrajit Patil, S. J. A Survey on IoT Based Security System. International Journal of Advanced Research in Computer and Communication Engineering, 2016,29-32.

[4] Katkar, S. V., Kamat, R. K., Kharade, K. G., \& Kharade, S. K. Inclusion of .NET framework for Calculating electrical parameters of solar cell. International Journal of Research in Electronics and Computer Engineering, 2019,1167-1169.

[5] Katkar, S. V., Kamat, R. K., Kharade, K. G., Kharade, S. K., \& Kamath, R. S. Simulation of $\mathrm{Cd}(\mathrm{SSe})$ Solar Cell Using Artificial Neural Network. International Journal of Advanced Science and Technology, XXIX(2), 2020,2583-2591.

[6] Katkar, S. V., Kharade, K. G., Kharade, S. K., \& Kamat, R. K. An Intelligent Way of Modeling and Simulation of WO3 for Supercapacitor. In N. Thapa, Recent Studies in Mathematics and Computer Science ,Hooghly, West Bengal, India: Book Publisher International,2020,109-117

[7] Kevin Otto, C. W. (2014). A comparison of the popular home automation technologies. EEE PES Conference on Innovative Smart Grid Technologies. Kuala Lumpur, Malaysia: IEEE Computer Society,2014,600-605.

[8] Kharade, K. G., Kamat, R. K., \& Kharade, S. K. Online Library Package to Boost the Functionality and Usability of the Existing Libraries. International Journal on Future Revolution in Computer Science \& Communication Engineering, 2019,5-7.

[9] Kharade, K. G., Kamat, R. K., Kharade, S. K., \& Katkar, S. V. Automation of Paper Setting Process to Improve Effectiveness of The Examination System of The University. Journal of Emerging Technologies and Innovative Research, 2019,490-493.

[10] Kharade, K. G., Mudholakr, R. R., Kamat, R. K., \& Kharade, S. K. Perovskite Solar Cell Simulation using Artificial Neural Network. International Journal of Emerging Technologies and Innovative Research, 2019,336-340.

[11] Kharade, K. G., Mudholkar, R. R., Kamat, R. K., \& Kharade, S. K. Artificial Neural Network Modeling of CZTS Solar Cell For Predicative Synthesis And Characterization. International Journal of Research And Analytical Reviews, 2019,997-1006.

[12] Kharade, S. K., Kamat, R. K., \& Kharade, K. G. Simulation of Dye Synthesized Solar Cell using Artificial Neural Network. International Journal of Engineering \& Advanced Technology (IJEAT), 2019,1316-1322.

[13] Kharade, S. K., Kamat, R. K., Kharade, K. G., Kamath, R. S., \& Shinde, S. A. Artificial Neural Network Based Efficiency Prediction and Its Impact on Dye Synthesized Solar Cell. International Journal of Recent Technology and Engineering, 2020,2696-2699.

[14] Kharade, S. K., Kharade, K. G., \& Kumbhar, V. S. Impact of Digital India on Various Sectors. Indian Journal of Innovation in Management And Excellence in Research, 2018,37-40.

[15] Kharade, S. K., Kharade, K. G., Kamat, R. K., \& Kumbhar, V. S. Setting Barrier to Removable Drive through Password Protection for Data Security. Our Heritage, 2020,19-23.

[16] Md. Wahidur Rahman, M. H.-A.-R. Embodiment of IOT based Smart Home Security System. International Journal for Research in Applied Science \& Engineering Technology,2018.

[17] N. Sriskanthan, F. T. Bluetooth based home automation system. Microprocess. Microsystems, 2002,281-289.

[18] R. K. Kodali, V. J.IoT based smart security and home automation system. 2016 International Conference on Computing, Communication and Automation (ICCCA), (pp. 1286-1289). 2016,Noida.

[19] R.P.Pandav, S. G. Security System And Home Appliances Control Using IoT. International Journal of Advance Research and Innovative Ideas in Education, 2018,4593-4597.

[20] Rao, G., Kumari, K., Shankar, D., \& Kharade, K. G. A comparative study of augmented realitybased head-worn display devices. Materials Today: Proceedings.,2021, 1-9.

[21] S.Hrushikesava Raju, D. R. IoT Based Home Automation System with Cloud Organizing. International Journal of Engineering \& Technology, 2018,412-415.

[22] Shaik Anwar, D. K. ( IOT based Smart Home Security System with Alert and Door Access Control using Smart Phone. International Journal of Engineering Research \& Technology , 2016,504-509.

[23] Kumar, V. A., Kumar, V. A., Malathi, S., Vengatesan, K., \& Ramakrishnan, M. (2018). Facial recognition system for suspect identification using a surveillance camera. Pattern Recognition and Image Analysis, 28(3), 410-420

[24] Tanaya, K. V. Home Security System using IoT. International Journal of Pure and Applied Mathematics,2018, 1863-1867. 